\title{
$\begin{array}{ll}\text { Research Square } & \begin{array}{l}\text { Preprints are preliminary reports that have not undergone peer review. } \\ \text { They should not be considered conclusive, used to inform clinical practice, } \\ \text { or referenced by the media as validated information. }\end{array}\end{array}$ \\ $\begin{array}{ll}\text { Research Square } & \begin{array}{l}\text { Preprints are preliminary reports that have not undergone peer review. } \\ \text { They should not be considered conclusive, used to inform clinical practice, } \\ \text { or referenced by the media as validated information. }\end{array}\end{array}$
}

\section{The Prognostic and Predictive Value of ESR1 Fusion Gene Transcripts in Primary Breast Cancer}

\section{Silvia R. Vitale}

University of Catania, Department of Clinical and Experimental Medicine and Center of Exper. Onco. and Hem., A.O.U. Policlinico "G. Rodolico- San Marco", Catania

\section{Kirsten Ruigrok-Ritstier}

Erasmus MC Cancer Institute, Erasmus University Medical Center, Department of Medical Oncology. Rotterdam

\section{A. Mieke Timmermans}

Erasmus MC Cancer Institute, Erasmus University Medical Center, Department of Medical Oncology. Rotterdam

\section{Renée Foekens}

Erasmus MC Cancer Institute, Erasmus University Medical Center, Department of Medical Oncology. Rotterdam

\section{Anita M.A.C. Trapman-Jansen}

Erasmus MC Cancer Institute, Erasmus University Medical Center, Department of Medical Oncology. Rotterdam

\section{Corine M. Beaufort}

Erasmus MC Cancer Institute, Erasmus University Medical Center, Department of Medical Oncology. Rotterdam

Paolo Vigneri

University of Catania, Department of Clinical and Experimental Medicine and Center of Exper. Onco. and Hem., A.O.U. Policlinico "G. Rodolico- San Marco", Catania

Stefan Sleijfer

Erasmus MC Cancer Institute, Erasmus University Medical Center, Department of Medical Oncology. Rotterdam

John W.M. Martens

Erasmus MC Cancer Institute, Erasmus University Medical Center, Department of Medical Oncology and Cancer Genomics Netherlands. Rotterdam Anieta M. Sieuwerts

Erasmus MC Cancer Institute, Erasmus University Medical Center, Department of Medical Oncology and Cancer Genomics Netherlands. Rotterdam Maurice P.H.M. Jansen ( $\sim$ m.p.h.m.jansen@erasmusmc.nl)

Erasmus MC Cancer Institute, Erasmus University Medical Center, Department of Medical Oncology. Rotterdam

\section{Research Article}

Keywords: fusion genes, ESR1, CCDC170, breast cancer, prognosis, RT-qPCR

Posted Date: December 1st, 2021

DOI: https://doi.org/10.21203/rs.3.rs-1110533/v1

License: (9) (7) This work is licensed under a Creative Commons Attribution 4.0 International License. Read Full License

Version of Record: A version of this preprint was published at BMC Cancer on February 12th, 2022. See the published version at https://doi.org/10.1186/s12885-022-09265-1. 


\section{Abstract}

Background: In breast cancer (BC), recurrent fusion genes of estrogen receptor alpha (ESR1) and AKAP12, ARMT1 and CCDC170 have been reported. In these gene fusions the ligand binding domain of ESR1 has been replaced by the transactivation domain of the fusion partner constitutively activating the receptor. As a result, these gene fusions can drive tumor growth hormone independently as been shown in preclinical models, but the clinical value of these fusions have not been reported. Here, we studied the prognostic and predictive value of different frequently reported ESR1 fusion transcripts in primary BC.

Methods: We evaluated 732 patients with primary BC (131 ESR1-negative and 601 ESR1-positive cases), including two ER-positive BC patient cohorts: one cohort of 322 patients with advanced disease who received first-line endocrine therapy (ET) (predictive cohort), and a second cohort of 279 patients with lymph node negative disease (LNN) who received no adjuvant systemic treatment (prognostic cohort). Fusion gene transcript levels were measured by reverse transcriptase quantitative PCR. The presence of the different fusion transcripts was associated, in uni- and multivariable Cox regression analysis taking along current clinic-pathological characteristics, to progression free survival (PFS) during first-line endocrine therapy in the predictive cohort, and disease-free survival (DFS) and overall survival (OS) in the prognostic cohort.

Results: The ESR1-CCDC170 fusion transcript was present in 27.6\% of the ESR1-positive BC subjects and in 2.3\% of the ESR1-negative cases. In the predictive cohort, none of the fusion transcripts were associated with response to first-line ET. In the prognostic cohort, the median DFS and OS were respectively 37 and 93 months for patients with an ESR1-CCDC170 exon 8 gene fusion transcript and respectively 91 and 212 months for patients without this fusion transcript. In a multivariable analysis, this ESR1-CCDC170 fusion transcript was an independent prognostic factor for DFS (HR) (95\% confidence interval (CI): 1.8 (1.2-2.8), $P=0.005)$ and OS (HR (95\% Cl: $1.7(1.1-2.7), P=0.023)$.

Conclusions: Our study shows that in primary BC only ESR1-CCDC170 exon 8 gene fusion transcript carries prognostic value. None of the ESR1 fusion transcripts, which are considered to have constitutive ER activity, was predictive for outcome in BC with advanced disease treated with endocrine treatment.

\section{Background}

The estrogen receptor (ER) plays a key role in cellular growth and tumor development in a large fraction of breast cancers. As a result, endocrine therapy has been and still is a successful treatment in patients with ESR1-positive (ESR1+) breast cancers (BC) [1]. However, in the metastatic setting, nearly half of the patients are de novo resistant to endocrine therapy while the remaining cases acquire resistance over time [2,3]. One of the primary characterized mechanisms of acquired resistance to endocrine therapy is the acquisition of mutations within the ligand-binding domain (LBD) of the estrogen receptor alpha gene (ESR1) activating the receptor constitutively thereby rendering tumor cells less dependent on estrogen [4-7]. Another mechanism that lead to less estrogen dependency of BC cells is the occurrence of ESR1 fusion proteins. Through analysis of RNA-sequencing data in breast cancer, recurrent intragenic fusions of $5^{\prime}$ end of ESR1 and the 3' ends of $A K A P 12, A R M T 1$ or $C C D C 170$ havebeen identified [8-13]. Gene fusions were preferentially detected in high-grade disease and/or endocrine-resistant forms of $\operatorname{ESR} 1+\mathrm{BC}[10,13]$. Despite the diversity among these fusions, they share a common structure retaining the hormone-independent transactivation domain as well as the DNA-binding domain whereas their ligand-binding domain is lost and replaced with a functional (transactivating) domain of the fusion partner, suggesting a pathological impact in ESR1+ BC [13]. However, the clinical significance of these fusions has not yet been properly addressed in uniform and well annotated cohorts.

In this study, we explored the occurrence of fusion transcripts of three of the most commonly reported fusion partners of ESR1 (i.e. CCDC170, AKAP12 and $A R M T 1)$ and determined the associations of their presence with clinical outcome in a cohort of 732 breast cancer patients allowing us to investigate their predictive value for endocrine treatment failure as well as their prognostic value.

\section{Methods}

\section{Study Cohorts}

The protocol to study biological markers associated with disease outcome was approved by the medical ethics committee of the Erasmus Medical Centre Rotterdam, The Netherlands (MEC 02.953) and was performed in accordance with the Code of Conduct of the Federation of Medical Scientific Societies in The Netherlands (https://www.federa.org/codes-conduct). The use of coded left-over material for scientific purposes and, therefore, for the greater good, does not require informed consent according to Dutch law and the new European general data protection regulation (GDPR).

In this retrospective study (see Fig. 1A for the consort diagram of the study), female patients were included, who underwent surgery for invasive primary breast cancer between 1980 and 2000 in the Netherlands. A further selection criterion was no previously diagnosed cancers with the exception of basal cell carcinoma or stage la/lb cervical cancer. Within this study, only data from sections of primary tumors with at least $30 \%$ invasive tumor cells were included. The details of tissue processing, RNA isolation, cDNA synthesis and QC of this cohort have been described previously [14, 15]. Tumor grade was assessed according to standard procedures at the time of inclusion. For the classification of patients' RNA samples regarding expression of the estrogen and progesterone receptors, as well as the human epidermal growth factor receptor 2 (HER2) amplification status, reverse transcriptase quantitative PCR (RTqPCR) was used with cut-offs previously described by us [14, 15].

The total cohort consisted of 732 patients with primary breast cancer (131 ESR1-negative and 601 ESR1-positive cases) (Fig. 1B). The clinical relevance of the gene fusion transcripts was evaluated in a predictive and a prognostic cohort of ESR1+ BC patients.

The predictive cohort consisted of 322 breast cancer patients with ESR 1+ primary tumors of which 235 patients received tamoxifen (40 mg daily) and 87 patients an aromatase inhibitor (Al: anastrozole, letrozole, exemestane [16]) as a 1st -line treatment for recurrent disease. Clinical response to tamoxifen 
therapy was defined as previously described $[14,17]$. The prognostic cohort included primary tumors from 279 lymph node negative (LNN) ESR1+ BC patients who had not received any systemic (neo) adjuvant therapy. Of note, 122 of these LNN ESR1+ patients were also included in the predictive cohort.

Clinicopathological characteristics of each of these 2 cohorts are described in Table 1. Association of ESR 1 fusions with clinical parameters of patients enrolled in the predictive cohort and in the prognostic cohort are reported in Table 2 and Table 3, respectively. 
Table 1

Clinicopathological characteristics of ESR1-positive breast cancer patient cohorts

\begin{tabular}{|c|c|c|c|}
\hline & \multicolumn{2}{|c|}{ Predictive Endocrine Therapy Cohorts } & \multirow{2}{*}{$\begin{array}{l}\text { Prognostic Cohort } \\
\text { Lymph node negative (LNN) }\end{array}$} \\
\hline & Tamoxifen & Aromatase inhibitors & \\
\hline Total & 235 & 87 & 279 \\
\hline Median age (range) & $61(29-90)$ & $66(35-86)$ & $55(26-85)$ \\
\hline \multicolumn{4}{|l|}{ Menopausal Status: } \\
\hline Premenopausal & 60 & 4 & 120 \\
\hline Postmenopausal & 175 & 82 & 159 \\
\hline \multicolumn{4}{|l|}{ Surgery: } \\
\hline Lumpectomy & 87 & 8 & 178 \\
\hline Ablation & 147 & 22 & 101 \\
\hline \multicolumn{4}{|c|}{ Adjuvant hormonal therapy: } \\
\hline no & 235 & 17 & 279 \\
\hline yes & 0 & 69 & 0 \\
\hline \multicolumn{4}{|c|}{ Adjuvant chemotherapy: } \\
\hline no & 198 & 69 & 279 \\
\hline yes & 37 & 18 & 0 \\
\hline \multicolumn{4}{|l|}{ Lymph node status: } \\
\hline negative & 102 & 20 & 279 \\
\hline positive & 81 & 49 & 0 \\
\hline not applicable (M1) & 42 & 17 & 0 \\
\hline \multicolumn{4}{|l|}{ Distant metastasis: } \\
\hline yes & 235 & 87 & 165 \\
\hline no & 0 & 0 & 114 \\
\hline \multicolumn{4}{|l|}{ Disease -Free Interval: } \\
\hline$<1$ year & 59 & 13 & 20 \\
\hline 1-3 year & 108 & 29 & 71 \\
\hline$>3$ year & 68 & 45 & 188 \\
\hline \multicolumn{4}{|c|}{ Median Follow-up time (in months): } \\
\hline after surgery & $62(3-272)$ & $103(7-295)$ & $93(5-337)$ \\
\hline after start therapy & $30(1-208)$ & $45(2-108)$ & \\
\hline \multicolumn{4}{|l|}{ PR status*: } \\
\hline Positive & 186 & 72 & 217 \\
\hline Negative & 48 & 15 & 62 \\
\hline \multicolumn{4}{|l|}{ HER2 status*: } \\
\hline Amplified & 31 & 10 & 43 \\
\hline Not amplified & 202 & 77 & 233 \\
\hline \multicolumn{4}{|l|}{ CCDC170 status*: } \\
\hline Positive & 206 & 81 & 252 \\
\hline Negative & 28 & 3 & 26 \\
\hline
\end{tabular}

PR: Progesterone receptor; ERBB2: Erb-B2 Receptor Tyrosine Kinase 2; CCDC170: coiled-coil domain containing 170; qRT-PCR: Real-Time quantitative reverse transcription PCR. 
Table 2

Association of ESR1 fusions with clinical parameters in the predictive cohort

Predictive Endocrine Therapy Cohorts

\begin{tabular}{|c|c|c|c|c|c|c|c|c|c|c|c|c|c|}
\hline \multirow[t]{2}{*}{ Parameters } & \multirow[t]{2}{*}{$\mathbf{n}$} & \multicolumn{2}{|c|}{$\begin{array}{l}\text { at least one } \\
\text { ESR1- } \\
\text { CCDC170 } \\
\text { (exon } 2 \text { to } 8 \text { ) } \\
\text { fusion }\end{array}$} & \multirow[t]{2}{*}{$\begin{array}{l}\text { P- } \\
\text { Value }\end{array}$} & \multicolumn{2}{|c|}{$\begin{array}{l}\text { ESR1- } \\
\text { CCDC170 } \\
\text { (exon 2) fusion }\end{array}$} & \multirow[t]{2}{*}{ PValue } & \multicolumn{2}{|c|}{$\begin{array}{l}\text { ESR1- } \\
\text { CCDC170 } \\
\text { (exon 8) } \\
\text { fusion }\end{array}$} & \multirow[t]{2}{*}{$\begin{array}{l}\text { P- } \\
\text { Value }\end{array}$} & \multicolumn{2}{|c|}{$\begin{array}{l}\text { ESR1- } \\
\text { AKAP12 }\end{array}$} & \multirow[t]{2}{*}{$\begin{array}{l}\text { P- } \\
\text { Value }\end{array}$} \\
\hline & & $\mathrm{n}$ & $\%$ & & $n$ & $\%$ & & $\mathrm{n}$ & $\%$ & & $n$ & $\%$ & \\
\hline All patients & 322 & 89 & $27.6 \%$ & & 50 & $15.5 \%$ & & 51 & $15.8 \%$ & & 13 & $4.0 \%$ & \\
\hline \multicolumn{14}{|l|}{ Age at start 1st line treatment (years) } \\
\hline$\leq 50$ & 63 & 19 & $30.2 \%$ & 0.63 & 12 & $19.0 \%$ & 0.62 & 8 & $12.7 \%$ & 0.029 & 1 & $1.6 \%$ & 0.36 \\
\hline$>50-\leq 70$ & 161 & 37 & $23.0 \%$ & & 23 & $14.3 \%$ & & 24 & $14.9 \%$ & & 7 & $4.3 \%$ & \\
\hline$>70$ & 98 & 33 & $33.7 \%$ & & 15 & $15.3 \%$ & & 19 & $19.4 \%$ & & 5 & $5.1 \%$ & \\
\hline \multicolumn{14}{|c|}{ Menopausal status at start of 1 st line treatment } \\
\hline Premenopausal & 64 & 17 & $26.6 \%$ & 0.82 & 10 & $15.6 \%$ & 0.99 & 8 & $12.5 \%$ & 0.41 & 1 & $1.6 \%$ & 0.26 \\
\hline Postmenopausal & 257 & 72 & $28.0 \%$ & & 40 & $15.6 \%$ & & 43 & $16.7 \%$ & & 12 & $4.7 \%$ & \\
\hline \multicolumn{14}{|l|}{ Surgery type } \\
\hline Lumpectomy & 95 & 25 & $26.3 \%$ & 0.79 & 14 & $14.7 \%$ & 0.90 & 15 & $15.8 \%$ & 0.83 & 2 & $2.1 \%$ & 0.89 \\
\hline Ablation & 169 & 42 & $24.9 \%$ & & 24 & $14.2 \%$ & & 25 & $14.8 \%$ & & 4 & $2.4 \%$ & \\
\hline \multicolumn{14}{|l|}{ Radiotherapy } \\
\hline No & 105 & 30 & $28.6 \%$ & 0.33 & 20 & $19.0 \%$ & 0.08 & 16 & $15.2 \%$ & 0.98 & 2 & $1.9 \%$ & 0.74 \\
\hline Yes & 159 & 37 & $23.3 \%$ & & 18 & $11.3 \%$ & & 24 & $15.1 \%$ & & 4 & $2.5 \%$ & \\
\hline \multicolumn{14}{|l|}{ Nodal status } \\
\hline No lymph nodes & 122 & 33 & $27.0 \%$ & 0.88 & 19 & $15.6 \%$ & 0.99 & 20 & $16.4 \%$ & 0.95 & 4 & $3.3 \%$ & 0.2 \\
\hline Positive lymph nodes & 130 & 38 & $29.2 \%$ & & 21 & $16.2 \%$ & & 22 & $16.9 \%$ & & 9 & $6.9 \%$ & \\
\hline $\begin{array}{l}\text { Tumor outside lymph } \\
\text { nodes }\end{array}$ & 53 & 15 & $28.3 \%$ & & 8 & $15.1 \%$ & & 7 & $13.2 \%$ & & 0 & $0.0 \%$ & \\
\hline Not applicable (M1) & 16 & 3 & $18.8 \%$ & & 2 & $12.5 \%$ & & 2 & $12.5 \%$ & & 0 & $0.0 \%$ & \\
\hline \multicolumn{14}{|l|}{ Pathological Tumor classification } \\
\hline pT1 & 85 & 22 & $25.9 \%$ & 0.60 & 13 & $15.3 \%$ & 0.21 & 14 & $16.5 \%$ & 0.90 & 2 & $2.4 \%$ & 0.36 \\
\hline pT2 + unknown & 186 & 50 & $26.9 \%$ & & 25 & $13.4 \%$ & & 30 & $16.1 \%$ & & 10 & $5.4 \%$ & \\
\hline pT3+pT4 & 51 & 17 & $33.3 \%$ & & 12 & $23.5 \%$ & & 7 & $13.7 \%$ & & 1 & $2.0 \%$ & \\
\hline \multicolumn{14}{|l|}{ Tumor grade } \\
\hline Poor & 160 & 45 & $28.1 \%$ & 0.36 & 27 & $16.9 \%$ & 0.60 & 27 & $16.9 \%$ & 0.60 & 7 & $4.4 \%$ & 0.078 \\
\hline Unknown & 81 & 18 & $22.2 \%$ & & 10 & $12.3 \%$ & & 10 & $12.3 \%$ & & 0 & $0.0 \%$ & \\
\hline Moderate/Good & 74 & 24 & $32.4 \%$ & & 13 & $17.6 \%$ & & 13 & $17.6 \%$ & & 5 & $6.8 \%$ & \\
\hline \multicolumn{14}{|l|}{ Tumor cell content } \\
\hline $30-49 \%$ & 27 & 7 & $25.9 \%$ & 0.96 & 4 & $14.8 \%$ & 0.99 & 2 & $7.4 \%$ & 0.25 & 2 & $7.4 \%$ & 0.63 \\
\hline $50-70 \%$ & 98 & 28 & $28.6 \%$ & & 15 & $15.3 \%$ & & 13 & $13.3 \%$ & & 4 & $4.1 \%$ & \\
\hline$>70 \%$ & 197 & 54 & $27.4 \%$ & & 31 & $15.7 \%$ & & 36 & $18.3 \%$ & & 7 & $3.6 \%$ & \\
\hline \multicolumn{14}{|l|}{ Hormone/ growth factor status (RT-qPCR)* } \\
\hline ESR1-negative & 0 & 0 & & & 0 & & & 0 & & & 0 & & \\
\hline ESR1-positive & 322 & 89 & $27.6 \%$ & & 50 & $15.5 \%$ & & 51 & $15.8 \%$ & & 13 & $4.0 \%$ & \\
\hline$P R$-negative & 63 & 18 & $28.6 \%$ & 0.87 & 11 & $17.5 \%$ & 0.65 & 11 & $17.5 \%$ & 0.70 & 6 & $9.5 \%$ & 0.014 \\
\hline$P R$-positive & 258 & 71 & $27.5 \%$ & & 39 & $15.1 \%$ & & 40 & $15.5 \%$ & & 7 & $2.7 \%$ & \\
\hline
\end{tabular}




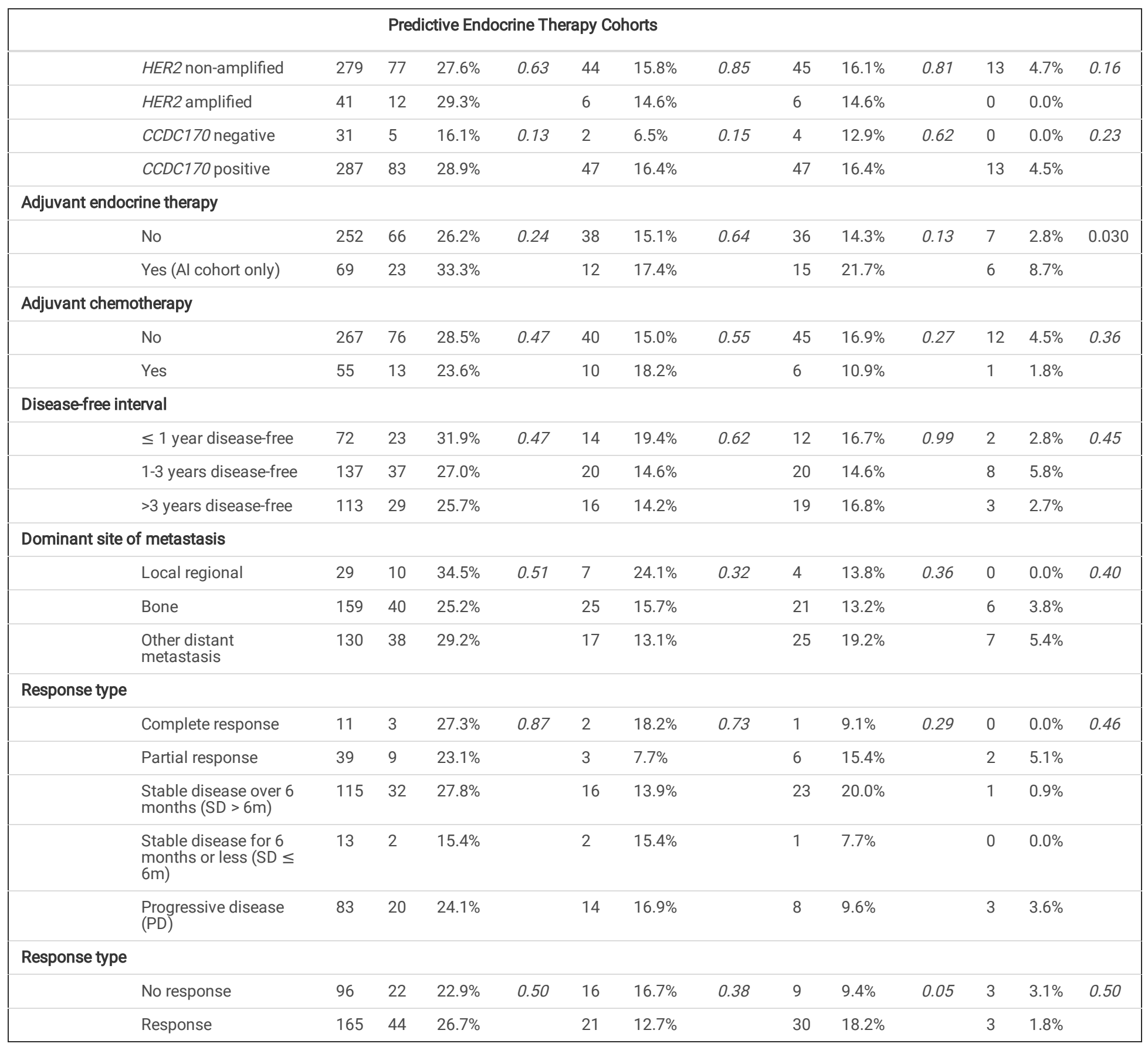

ESR1: Estrogen Receptor 1 gene; ERBB2: Erb-B2 Receptor Tyrosine Kinase 2; CCDC170: coiled-coil domain containing 170. Statistically significant differences are indicated in bold. 
Associations of ESR1 fusions with clinical parameters in prognostic clinical cohort

\section{LNN ESR+ Prognostic cohort}

\begin{tabular}{|c|c|c|c|c|c|c|c|c|c|c|c|c|c|c|}
\hline \multirow[t]{3}{*}{ Parameters } & & \multirow[t]{3}{*}{$\mathbf{n}$} & \multirow{2}{*}{\multicolumn{2}{|c|}{$\begin{array}{l}\text { at least one } \\
\text { ESR1-CCDC170 } \\
\text { (exon } 2 \text { to } 8 \text { ) } \\
\text { fusion }\end{array}$}} & \multirow[t]{3}{*}{$\begin{array}{l}\mathrm{P}- \\
\text { value }\end{array}$} & \multirow{2}{*}{\multicolumn{2}{|c|}{$\begin{array}{l}\text { ESR1-CCDC170 } \\
\text { (exon 2) fusion }\end{array}$}} & \multirow[t]{3}{*}{$\begin{array}{l}\mathrm{P} \text { - } \\
\text { value }\end{array}$} & \multirow{2}{*}{\multicolumn{2}{|c|}{$\begin{array}{l}\text { ESR1-CCDC170 } \\
\text { (exon 8) fusion }\end{array}$}} & \multirow[t]{3}{*}{$\begin{array}{l}\mathrm{P}- \\
\text { value }\end{array}$} & \multirow{2}{*}{\multicolumn{2}{|c|}{$\begin{array}{l}\text { ESR1- } \\
\text { AKAP12 }\end{array}$}} & \multirow[t]{3}{*}{$\begin{array}{l}\mathrm{P} \text { - } \\
\text { value }\end{array}$} \\
\hline & & & & & & & & & & & & & & \\
\hline & & & $\mathrm{n}$ & $\%$ & & $\mathrm{n}$ & $\%$ & & $\mathrm{n}$ & $\%$ & & $\mathrm{n}$ & $\%$ & \\
\hline All patients & & 279 & 70 & $25.1 \%$ & & 33 & $11.8 \%$ & & 39 & $14.0 \%$ & & 5 & $1.8 \%$ & \\
\hline \multicolumn{15}{|c|}{ Age at primary surgery } \\
\hline & $\leq 40$ years & 29 & 6 & $20.7 \%$ & 0.001 & 4 & $13.8 \%$ & 0.38 & 4 & $13.8 \%$ & 0.26 & 1 & $3.4 \%$ & 0.27 \\
\hline & $41-50$ years & 81 & 11 & $13.6 \%$ & & 5 & $6.2 \%$ & & 5 & $6.2 \%$ & & 0 & $0.0 \%$ & \\
\hline & $51-70$ years & 125 & 36 & $28.8 \%$ & & 16 & $12.8 \%$ & & 21 & $16.8 \%$ & & 3 & $2.4 \%$ & \\
\hline & $>70$ years & 44 & 17 & $38.6 \%$ & & 8 & $18.2 \%$ & & 9 & $20.5 \%$ & & 1 & $2.3 \%$ & \\
\hline \multicolumn{15}{|c|}{ Menopausal status } \\
\hline & Premenopausal & 120 & 19 & $15.8 \%$ & 0.002 & 10 & $8.3 \%$ & 0.12 & 11 & $9.2 \%$ & 0.044 & 1 & $0.8 \%$ & 0.29 \\
\hline & Postmenopausal & 159 & 51 & $32.1 \%$ & & 23 & $14.5 \%$ & & 28 & $17.6 \%$ & & 4 & $2.5 \%$ & \\
\hline \multicolumn{15}{|l|}{ Surgery type } \\
\hline & Lumpectomy & 178 & 44 & $24.7 \%$ & 0.85 & 19 & $10.7 \%$ & 0.43 & 25 & $14.0 \%$ & 0.97 & 4 & $2.2 \%$ & 0.45 \\
\hline & Ablation & 101 & 26 & $25.7 \%$ & & 14 & $13.9 \%$ & & 14 & $13.9 \%$ & & 1 & $1.0 \%$ & \\
\hline \multicolumn{15}{|l|}{ Radiotherapy } \\
\hline & No & 84 & 24 & $28.6 \%$ & 0.38 & 14 & $16.7 \%$ & 0.10 & 12 & $14.3 \%$ & 0.92 & 1 & $1.2 \%$ & 0.62 \\
\hline & Yes & 195 & 46 & $23.6 \%$ & & 19 & $9.7 \%$ & & 27 & $13.8 \%$ & & 4 & $2.1 \%$ & \\
\hline \multicolumn{15}{|l|}{ Nodal status } \\
\hline & No lymph nodes & 279 & 70 & $25.1 \%$ & & 33 & $11.8 \%$ & & 39 & $14.0 \%$ & & 5 & $1.8 \%$ & \\
\hline & $\begin{array}{l}\text { Positive lymph } \\
\text { nodes }\end{array}$ & 0 & 0 & & & 0 & & & 0 & & & 0 & & \\
\hline & $\begin{array}{l}\text { Tumor outside } \\
\text { lymph nodes }\end{array}$ & 0 & 0 & & & 0 & & & 0 & & & 0 & & \\
\hline \multicolumn{15}{|c|}{ Pathological Tumor classification } \\
\hline & pT1 & 151 & 34 & $22.5 \%$ & 0.28 & 17 & $11.3 \%$ & 0.61 & 16 & $10.6 \%$ & 0.08 & 2 & $1.3 \%$ & 0.1 \\
\hline & pT2 + unknown & 119 & 32 & $26.9 \%$ & & 14 & $11.8 \%$ & & 20 & $16.8 \%$ & & 2 & $1.7 \%$ & \\
\hline & pT3+pT4 & 9 & 4 & $44.4 \%$ & & 2 & $22.2 \%$ & & 3 & $33.3 \%$ & & 1 & $11.1 \%$ & \\
\hline \multicolumn{15}{|l|}{ Tumor grade } \\
\hline & Poor & 131 & 36 & $27.5 \%$ & 0.60 & 21 & $16.0 \%$ & 0.06 & 21 & $16.0 \%$ & 0.56 & 3 & $2.3 \%$ & 0.84 \\
\hline & Unknown & 81 & 20 & $24.7 \%$ & & 9 & $11.1 \%$ & & 11 & $13.6 \%$ & & 1 & $1.2 \%$ & \\
\hline & Moderate/Good & 67 & 14 & $20.9 \%$ & & 3 & $4.5 \%$ & & 7 & $10.4 \%$ & & 1 & $1.5 \%$ & \\
\hline \multicolumn{15}{|c|}{ Tumor cell content } \\
\hline & $30-49 \%$ & 31 & 9 & $29.0 \%$ & 0.82 & 6 & $19.4 \%$ & 0.38 & 4 & $12.9 \%$ & 0.86 & 1 & $3.2 \%$ & 0.81 \\
\hline & $50-70 \%$ & 69 & 16 & $23.2 \%$ & & 7 & $10.1 \%$ & & 11 & $15.9 \%$ & & 1 & $1.4 \%$ & \\
\hline & $>70 \%$ & 179 & 45 & $25.1 \%$ & & 20 & $11.2 \%$ & & 24 & $13.4 \%$ & & 3 & $1.7 \%$ & \\
\hline \multicolumn{15}{|c|}{$\begin{array}{l}\text { Hormone/ growth factor status (RT- } \\
\text { qPCR)** }\end{array}$} \\
\hline & ESR1 negative & 0 & 0 & & & 0 & & & 0 & & & 0 & & \\
\hline & ESR1 positive & 279 & 70 & $25.1 \%$ & & 33 & $11.8 \%$ & & 39 & $14.0 \%$ & & 5 & $1.8 \%$ & \\
\hline & $P R$ negative & 62 & 16 & $25.8 \%$ & 0.88 & 9 & $14.5 \%$ & 0.46 & 8 & $12.9 \%$ & 0.78 & 2 & $3.2 \%$ & 0.93 \\
\hline & $P R$ positive & 217 & 54 & $24.9 \%$ & & 24 & $11.1 \%$ & & 31 & $14.3 \%$ & & 3 & $1.4 \%$ & \\
\hline
\end{tabular}




\begin{tabular}{|c|c|c|c|c|c|c|c|c|c|c|c|c|c|}
\hline \multirow[b]{2}{*}{$\begin{array}{l}\text { HER2 non- } \\
\text { amplified }\end{array}$} & \multicolumn{9}{|c|}{ LNN ESR+ Prognostic cohort } & \multirow[b]{2}{*}{0.61} & \multirow[b]{2}{*}{4} & \multirow[b]{2}{*}{$1.7 \%$} & \multirow[b]{2}{*}{0.78} \\
\hline & 233 & 62 & $26.6 \%$ & 0.15 & 29 & $12.4 \%$ & 0.30 & 34 & $14.6 \%$ & & & & \\
\hline HER2 amplified & 43 & 7 & $16.3 \%$ & & 3 & $7.0 \%$ & & 5 & $11.6 \%$ & & 1 & $2.3 \%$ & \\
\hline $\begin{array}{l}C C D C 170 \\
\text { negative }\end{array}$ & 26 & 4 & $15.4 \%$ & 0.23 & 2 & $7.7 \%$ & 0.49 & 3 & $11.5 \%$ & 0.70 & 0 & $0.0 \%$ & 0.47 \\
\hline$C C D C 170$ positive & 252 & 66 & $26.2 \%$ & & 31 & $12.3 \%$ & & 36 & $14.3 \%$ & & 5 & $2.0 \%$ & \\
\hline \multicolumn{14}{|l|}{ Disease-free interval } \\
\hline $\begin{array}{l}\leq 1 \text { year disease- } \\
\text { free }\end{array}$ & 20 & 7 & $35.0 \%$ & 0.011 & 2 & $10.0 \%$ & 0.08 & 4 & $20.0 \%$ & 0.006 & 0 & $0.0 \%$ & 0.57 \\
\hline $\begin{array}{l}\text { 1-3 years disease- } \\
\text { free }\end{array}$ & 71 & 18 & $25.4 \%$ & & 10 & $14.1 \%$ & & 14 & $19.7 \%$ & & 2 & $2.8 \%$ & \\
\hline $\begin{array}{l}>3 \text { years disease- } \\
\text { free }\end{array}$ & 188 & 45 & $23.9 \%$ & & 21 & $11.2 \%$ & & 21 & $11.2 \%$ & & 3 & $1.6 \%$ & \\
\hline \multicolumn{14}{|l|}{ Adjuvant endocrine therapy } \\
\hline No & 279 & 66 & $23.7 \%$ & & 33 & $11.8 \%$ & & 39 & $14.0 \%$ & & 5 & $1.8 \%$ & \\
\hline Yes & 0 & 0 & & & 0 & & & 0 & & & 0 & & \\
\hline \multicolumn{14}{|l|}{ Adjuvant chemotherapy } \\
\hline No & 279 & 66 & $23.7 \%$ & & 33 & $11.8 \%$ & & 39 & $14.0 \%$ & & 5 & $1.8 \%$ & \\
\hline Yes & 0 & 0 & & & 0 & & & 0 & & & 0 & & \\
\hline
\end{tabular}

ESR1: Estrogen Receptor 1 gene; ERBB2: Erb-B2 Receptor Tyrosine Kinase 2; CCDC170: coiled-coil domain containing 170. Statistically significant differences are indicated in bold.

\section{RNA isolation and RT-qPCR}

Total RNA isolation from human breast cancer tissue, breast cancer cell line models and quality control were performed as previously described [14]. Next, cDNA was generated by a cycle at $48^{\circ} \mathrm{C}$ for 30 minutes with RevertAid H-minus (Applied Biosystems, Carlsbad, CA), according to the manufacturer's instructions. The cDNA was then pre-amplified for specific genes as previously described [14]. Briefly, $2 \mu \mathrm{L}$ of cDNA (0.1 to $1 \mathrm{ng} / \mu \mathrm{L})$ was subject to a preamplification of 15 cycles using a multiple loci target-specific amplification for ESR 1 fusions with AKAP12, ARMT1 and CCDC170 and two reference genes, the Epithelian Cell Adhesion Molecule (EPCAM) and the Hypoxanthine Phosphoribosyltransferase 1 (HPRT1), with TaqMan PreAmp Master Mix (Applied Biosystems), as recommended by the manufacturer. Pre-amplified products were then diluted 12-fold in LoTE buffer (3 mM Tris-HCl/0.2 mM EDTA, pH 8.0) prior to downstream analysis. Next, $5 \mu \mathrm{L}$ diluted pre-amplified samples were subjected to a TaqMan probe based real-time quantitative PCR (qPCR) for each gene combination, according to the manufacturer's instructions, in a MX3000P Real-Time PCR System (Agilent, Santa Clara, CA). The average expression of HPRT1 and the epithelial marker EPCAM was used as reference to control RNA quality and calculate the expression levels of target genes, as previously described [14]. Only those samples with a $\triangle \mathrm{Cq}>25$ relative to the two reference genes were used for further evaluation of gene fusions, as previously described [18-20]. Additional File 1 describes the primer sets used in the pre-amplification combination, as well as the Taqman qPCR used to quantify the fusions and reference genes. For ESR1-CCDC170 fusion transcripts, the variants in which exon 2 of ESR1 is fused to the coding region (exon 2 to 11 ) of CCDC170 were examined (E2-E2, E2-E3, E2-E4, E2-E5, E2-E6, E2-E7, E2-E8, E2-E10 and E2-E11). Samples with a $\Delta$ Cq $>25$ relative to the reference genes were afterwards validated by MultiNA analysis (Shimadzu Europe, Duisburg, Germany). Only those samples with a MultiNA fusion product of the expected size were considered positive for the fusion transcripts (Additional File 2). The detection of ESR1-CCDC170 fusion transcripts with RT-qPCR and MultiNA analysis was verified and confirmed in a set of fusion-positive reported breast cancer cell lines (Additional File 3 - 4 - 5).

\section{Statistical analysis}

All data were entered in SPSS version 24 (IBM Corp., Armonk, NY, USA) to generate the tables and perform the statistical analyses. For contingency tables, the Pearson Chi-Square Test was used. All $P$-values are 2-sided and $P<0.05$ was considered statistically significant.

\section{Results}

\section{Association of ESR1 with its CCDC170, AKAP12 and ARMT1 fusion partner}

The presence of the ESR1 fusions with AKAP12, ARMT1 and CCDC170 (exon 2 to exon 11) was evaluated in breast cancer tissue samples from 732 breast cancer patients. Fusion transcripts were predominantly detected in the ESR1+ population, with CCDC170, AKAP12 or ARMT1 fusion transcripts observed in $27.6 \%, 4.04 \%$ and $1.4 \%$ of the ER-positive cases respectively, and seen in $2.3 \%, 0.8 \%$ and $0 \%$ of the ESR 1 - cases respectively $(P<0.001$, Fisher's exact test two tailed. Table 4 and Additional File 6). In ER-positive tumors, full length ESR1 and $C C D C 170 \mathrm{mRNA}$ levels were strongly correlated $\left(\mathrm{R}^{2}=0.31, P<0.0001\right)$ 
(Additional File 7A) and transcript levels of both were significantly higher in the group of samples with an ESR1-CCDC170 fusion transcript when compared to the group without [Student T-Test $P=0.0316$ and 0.0001 , respectively (Additional File 7B).

Table 4

Prevalence of ESR1 fusions in the different analyzed cohorts.

\begin{tabular}{|c|c|c|c|c|c|c|c|c|c|c|c|c|c|c|c|c|}
\hline & & & \multicolumn{3}{|c|}{$\begin{array}{l}\text { At least one } \\
\text { ESR1-CCDC170 } \\
\text { (exon } 2 \text { to } 8 \text { ) fusion }\end{array}$} & & \multicolumn{3}{|c|}{$\begin{array}{l}\text { ESR1-CCDC170 } \\
\text { exon } 2\end{array}$} & \multicolumn{3}{|c|}{$\begin{array}{l}\text { ESR1-CCDC170 } \\
\text { exon } 8\end{array}$} & \multicolumn{4}{|c|}{ ESR1_AKAP12 } \\
\hline & $\begin{array}{l}\text { Total } \\
\text { Count }\end{array}$ & & no & yes & $\%$ & $\begin{array}{l}\% \text { of } \\
\text { total } \\
\text { count }\end{array}$ & no & yes & $\%$ & no & yes & $\%$ & no & yes & $\%$ & $\begin{array}{l}\% \text { of } \\
\text { total } \\
\text { count }\end{array}$ \\
\hline \multirow[t]{2}{*}{$\begin{array}{l}\text { All samples } \\
\text { studied }\end{array}$} & 788 & $\begin{array}{l}\text { ESR1 } \\
\text { negative }\end{array}$ & 128 & 3 & $2.3 \%$ & $22.0 \%$ & 128 & 3 & $2.29 \%$ & 130 & 1 & $0.76 \%$ & 130 & 1 & $0.76 \%$ & \multirow[t]{2}{*}{$2.7 \%$} \\
\hline & & $\begin{array}{l}\text { ESR1 } \\
\text { positive }\end{array}$ & 487 & 170 & $25.9 \%$ & & 565 & 92 & $14.00 \%$ & 556 & 101 & $15.37 \%$ & 637 & 20 & $3.04 \%$ & \\
\hline \multirow[t]{2}{*}{$\begin{array}{l}\text { 1st line } \\
\text { Tamoxifen }\end{array}$} & 235 & $\begin{array}{l}\text { ESR1 } \\
\text { negative }\end{array}$ & 0 & 0 & $0 \%$ & $24.7 \%$ & 0 & 0 & $0 \%$ & 0 & 0 & $0 \%$ & 0 & 0 & $0 \%$ & \multirow[t]{2}{*}{$2.6 \%$} \\
\hline & & $\begin{array}{l}\text { ESR1 } \\
\text { positive }\end{array}$ & 177 & 58 & $24.7 \%$ & & 204 & 31 & $13.19 \%$ & 201 & 34 & $14.47 \%$ & 229 & 6 & $2.55 \%$ & \\
\hline \multirow[t]{2}{*}{1 st line Al } & 87 & $\begin{array}{l}\text { ESR1 } \\
\text { negative }\end{array}$ & 0 & 0 & $0 \%$ & $35.6 \%$ & 0 & 0 & $0 \%$ & 0 & 0 & $0 \%$ & 0 & 0 & $0 \%$ & \multirow[t]{2}{*}{$8.0 \%$} \\
\hline & & $\begin{array}{l}\text { ESR1 } \\
\text { positive }\end{array}$ & 56 & 31 & $35.6 \%$ & & 68 & 19 & $21.84 \%$ & 70 & 17 & $19.54 \%$ & 80 & 7 & $8.05 \%$ & \\
\hline \multirow{2}{*}{$\begin{array}{l}1 \text { st line } \\
\text { endocrine } \\
\text { cohort }\end{array}$} & 322 & $\begin{array}{l}\text { ESR1 } \\
\text { negative }\end{array}$ & 0 & 0 & $0 \%$ & $27.6 \%$ & 0 & 0 & $0 \%$ & 0 & 0 & $0 \%$ & 0 & 0 & $0 \%$ & \multirow[t]{2}{*}{$4.0 \%$} \\
\hline & & $\begin{array}{l}\text { ESR1 } \\
\text { positive }\end{array}$ & 233 & 89 & $27.6 \%$ & & 272 & 50 & $15.53 \%$ & 271 & 51 & $15.84 \%$ & 309 & 13 & $4.04 \%$ & \\
\hline \multirow[t]{2}{*}{ Primary cohort } & 566 & $\begin{array}{l}\text { ESR1 } \\
\text { negative }\end{array}$ & 113 & 3 & $2.6 \%$ & $17.8 \%$ & 113 & 3 & $2.59 \%$ & 115 & 1 & $0.86 \%$ & 115 & 1 & $0.86 \%$ & \multirow[t]{2}{*}{$1.9 \%$} \\
\hline & & $\begin{array}{l}\text { ESR1 } \\
\text { positive }\end{array}$ & 352 & 98 & $21.8 \%$ & & 403 & 47 & $10.44 \%$ & 392 & 58 & $12.89 \%$ & 440 & 10 & $2.22 \%$ & \\
\hline \multirow[t]{2}{*}{$\begin{array}{l}\text { Primary LNP } \\
\text { cohort }\end{array}$} & 192 & $\begin{array}{l}\text { ESR1 } \\
\text { negative }\end{array}$ & 26 & 0 & $0.0 \%$ & $15.6 \%$ & 26 & 0 & $0.00 \%$ & 26 & 0 & $0.00 \%$ & 26 & 0 & $0.00 \%$ & \multirow[t]{2}{*}{$2.6 \%$} \\
\hline & & $\begin{array}{l}\text { ESR1 } \\
\text { positive }\end{array}$ & 136 & 30 & $18.1 \%$ & & 152 & 14 & $8.43 \%$ & 148 & 18 & $10.84 \%$ & 161 & 5 & $3.01 \%$ & \\
\hline \multirow[t]{2}{*}{$\begin{array}{l}\text { Primary LNN } \\
\text { cohort }\end{array}$} & 369 & $\begin{array}{l}\text { ESR1 } \\
\text { negative }\end{array}$ & 87 & 3 & $3.3 \%$ & $18.7 \%$ & 87 & 3 & $3.33 \%$ & 89 & 1 & $1.11 \%$ & 89 & 1 & $1.11 \%$ & \multirow[t]{2}{*}{$1.6 \%$} \\
\hline & & $\begin{array}{l}\text { ESR1 } \\
\text { positive }\end{array}$ & 213 & 66 & $23.7 \%$ & & 246 & 33 & $11.83 \%$ & 240 & 39 & $13.98 \%$ & 274 & 5 & $1.79 \%$ & \\
\hline \multirow{2}{*}{$\begin{array}{l}\text { Normal breast } \\
\text { tissue of } \\
\text { breast cancer } \\
\text { patients }\end{array}$} & 36 & $\begin{array}{l}\text { ESR1 } \\
\text { negative }\end{array}$ & 0 & 0 & $0 \%$ & $66.7 \%$ & 0 & 0 & $0 \%$ & 0 & 0 & $0 \%$ & 0 & 0 & & \multirow[t]{2}{*}{$0.0 \%$} \\
\hline & & $\begin{array}{l}\text { ESR1 } \\
\text { positive }\end{array}$ & 12 & 24 & $66.7 \%$ & & 18 & 18 & $50.0 \%$ & 23 & 13 & $36.1 \%$ & 36 & 0 & $0.0 \%$ & \\
\hline \multirow{2}{*}{$\begin{array}{l}\text { Tissue of } \\
\text { breast } \\
\text { fibroadenoma's }\end{array}$} & 16 & $\begin{array}{l}\text { ESR1 } \\
\text { negative }\end{array}$ & 0 & 0 & $0 \%$ & $25.0 \%$ & 0 & 0 & $0 \%$ & 0 & 0 & $0 \%$ & 0 & 0 & $0 \%$ & \multirow[t]{2}{*}{$0.0 \%$} \\
\hline & & $\begin{array}{l}\text { ESR1 } \\
\text { positive }\end{array}$ & 12 & 4 & $20.0 \%$ & & 16 & 0 & $0.0 \%$ & 16 & 4 & $20.0 \%$ & 16 & 0 & $0.0 \%$ & \\
\hline \multirow[t]{2}{*}{$\begin{array}{l}\text { Tissue of } \\
\text { breast DCIS }\end{array}$} & 13 & $\begin{array}{l}\text { ESR1 } \\
\text { negative }\end{array}$ & 0 & 0 & $0 \%$ & $7.7 \%$ & 0 & 0 & $0 \%$ & 0 & 0 & $0 \%$ & 0 & 0 & $0 \%$ & \multirow[t]{2}{*}{$0.0 \%$} \\
\hline & & $\begin{array}{l}\text { ESR1 } \\
\text { positive }\end{array}$ & 12 & 1 & $7.7 \%$ & & 13 & 0 & $0.0 \%$ & 13 & 0 & $0.0 \%$ & 13 & 0 & $0.0 \%$ & \\
\hline \multirow{2}{*}{$\begin{array}{l}\text { Normal breast } \\
\text { tissue of } \\
\text { healthy women }\end{array}$} & 10 & $\begin{array}{l}\text { ESR1 } \\
\text { negative }\end{array}$ & 0 & 0 & $0 \%$ & $10.0 \%$ & 0 & 0 & $0 \%$ & 0 & 0 & $0 \%$ & 0 & 0 & $0 \%$ & \multirow[t]{2}{*}{$0.0 \%$} \\
\hline & & $\begin{array}{l}\text { ESR1 } \\
\text { positive }\end{array}$ & 9 & 1 & $10.0 \%$ & & 9 & 1 & $10.0 \%$ & 10 & 0 & $0.0 \%$ & 10 & 0 & $0.0 \%$ & \\
\hline
\end{tabular}

ESR1: Estrogen Receptor 1 gene; Al: Aromatase Inhibitor; LNP: Lymph node positive; LNN: Lymph node negative; DCIS: ductal carcinoma in situ. Statistically significant differences are indicated in bold. 
While AKAP12 and ARMT1 fusion transcripts were not found in 36 non-malignant breast tissues taken at a distance of the primary tumor, ESR1-CCDC170 fusion transcripts were detected in $67 \%$ of these normal breast tissues of patients with diagnosed breast cancer (Table 4). Note that CCDC170, but not ESR1, mRNA levels were significantly higher in these normal (adjacent to tumor) tissues than in cancer tissue (Kruskal Wallis Test $P<0.0001$, (Fig. 2). To investigate this unexpectedly high incidence in more detail, we analyzed normal breast tissues of ten women without diagnosed breast cancer, 16 benign fibroadenomas and 13 ductal carcinomas in situ (DCIS) tissues, all of them ESR1-positive. In addition, we measured the fusion transcripts in three sets of patient-matched normal breast and primary tumor carcinomas and four patient-matched sets of primary breast tumors and metastatic lymph nodes, also all ESR1-positive. In none of these cases did we detect an ESR1 fusion transcripts with AKAP12 or ARMT1. However, one of the breast tissues of women without breast cancer diagnosis (10\%) showed ESR1-CCDC170 exon 2 (E2-E2) fusion transcripts, one of the DCIS cases (7.7\%) had ESR1-CCDC170 exon 6 (E2-E6) fusion transcripts, and four patients with fibroadenoma (25\%) had ESR1-CCDC170 exon 8 (E2-E8) fusion transcripts (Table 4 and Additional File 6). For one out of the three matched normal-tumor cases we found an ESR1-CCDC170 exon 8 fusion in both the primary tumor and the normal breast tissue taken at a distance from the primary tumor. Finally, for two out of the four patients of which we had a matched primary tumor and lymph node metastasis, an ESR1-CCDC170 exon 2 fusion was present in both the primary tumor and the lymph node metastasis.

\section{Prevalence of ESR1 fusion genes in breast tumor tissues}

Since fusion transcripts were predominantly detected in the ESR1+ population, we decided to investigate the clinical relevance of these transcripts in primary tumors. To this end, we stratified ESR1+ patients in two distinct cohort: a predictive cohort of advanced BC patients treated with first-line endocrine therapy and a prognostic cohort of primary BC patients with lymph node negative disease (LNN) who did not receive any adjuvant systemic treatment.

In these two ESR1+ cohorts, ESR1-ARMT1 fusion transcripts were detected in four patients of the predictive cohort (1.2\%) and in three patients of the prognostic cohort (1.1\%). Due to the low incidence of this ESR1-ARMT1 fusion transcript, it was not further pursued. ESR1-AKAP12 fusion transcripts were more common, and observed in 13 patients of the predictive cohort (4.0\%) and in five patients of the prognostic cohort (1.8\%). The ESR1-CCDC170 fusion transcripts, however, were the most prevalent and detected in the predictive cohort in 89 patients (27.6\%) and in the prognostic cohort in 70 patients (25.1\%). Interestingly, all patients harboring an ESR1-ARMT1 or an ESR1-AKAP12 fusion were also positive for an ESR1-CCDC170 rearranged transcript. Moreover, we noticed the coexistence of the three fusions in two subjects. Of all the breast tissue samples studied, the most prominent ESR1-CCDC170 fusion transcripts found involved exon 2 of ESR1 fused with exon 2 (14\%) and exon 8 (15.37\%) of CCDC170 (Table 4).

\section{Association of ESR1 fusion genes with DFS and OS in the prognostic cohort}

The presence of ESR1-CCDC170 fusion transcripts in the primary tumor of our ESR1+LNN patients predicted a shorter disease-free survival in a Cox proportional hazards regression survival analysis (HR $\pm 95 \% \mathrm{Cl}: 1.44(1.01-2.05), P=0.044)$ (Table 5). We decided to investigate the two frequently present ESR1-CCDC170 fusion transcripts (E2-E2 and E2-E8). Analyzing the ESR1-CCDC170 exon 2 and exon 8 separately, showed that the fusion with exon 8 of $C C D C 170$ on its own associated with a short disease free survival (DFS; HR $\pm 95 \% \mathrm{Cl}: 1.95(1.30-2.93), P=0.001)$. No association with disease free survival was seen for ESR1-AKAP12 fusion transcripts (HR $\pm 95 \% \mathrm{Cl}: 1.23(0.39-3.87), P=0.72)$. Concerning overall survival, only the presence of an ESR1-CCDC170 exon 8 fusion predicted a shorter overall survival time (HR $\pm 95 \% \mathrm{Cl}: 1.85(1.18-2.90, P=0.007)$ The DFS and OS Kaplan Meier curves as a function of ESR1$C C D C 170$ exon 8 fusion transcripts are shown in Fig. 3A and Fig. 3B, respectively. A multivariate analysis was performed in which age at primary surgery, pathological tumor classification, tumor grade, progesterone receptor and HER2 status were included. The analysis revealed HER2 status as a significant prognostic factor for overall survival, but not for DFS $(P=0.36)$ (Table 5). In this analyses, the presence of ESR 1-CCDC170 exon 8 fusion transcripts was an independent prognostic factor for both DFS (HR $\pm 95 \% \mathrm{Cl}: 1.82(1.20-2.75), P=0.005)$ and OS (HR $\pm 95 \% \mathrm{Cl}: 1.71(1.08-2.72), P=0.001)$. 
Table 5

Uni- and multivariate Cox proportional hazards regression survival analysis

\begin{tabular}{|c|c|c|c|c|c|c|c|c|c|c|c|c|c|c|c|c|c|}
\hline \multirow[b]{2}{*}{ Parameters } & \multirow[b]{2}{*}{$\mathbf{n}$} & \multicolumn{4}{|c|}{ Univariate model DFS } & \multicolumn{4}{|c|}{ Multivariate model DFS } & \multicolumn{4}{|c|}{ Univariate model OS } & \multicolumn{4}{|c|}{ Multivariate model OS } \\
\hline & & HR & \multicolumn{2}{|c|}{$(95 \% \mathrm{Cl})$} & $\mathrm{P}$ & HR & \multicolumn{2}{|c|}{$(95 \% \mathrm{Cl})$} & $\mathrm{P}$ & HR & \multicolumn{2}{|c|}{$(95 \% \mathrm{Cl})$} & $\mathrm{P}$ & HR & \multicolumn{2}{|c|}{$(95 \% \mathrm{Cl})$} & $\mathrm{P}$ \\
\hline & 279 & & & & & & & & & & & & & & & & \\
\hline $\begin{array}{l}\text { Age at primary } \\
\text { surgery }\end{array}$ & & & & & 0.25 & & & & 0.31 & & & & 0.19 & & & & 0.18 \\
\hline$\leq 40$ years & 29 & 1 & & & & 1 & & & & 1 & & & & 1 & & & \\
\hline $41-50$ years & 81 & 0.59 & 0.35 & 1.00 & 0.049 & 0.60 & 0.35 & 1.02 & 0.06 & 0.53 & 0.30 & 0.96 & 0.036 & 0.51 & 0.28 & 0.94 & 0.032 \\
\hline $51-70$ years & 125 & 0.73 & 0.44 & 1.19 & 0.20 & 0.72 & 0.44 & 1.18 & 0.19 & 0.75 & 0.44 & 1.28 & 0.30 & 0.72 & 0.42 & 1.26 & 0.25 \\
\hline$>70$ years & 44 & 0.78 & 0.43 & 1.40 & 0.41 & 0.71 & 0.39 & 1.28 & 0.25 & 0.73 & 0.37 & 1.43 & 0.35 & 0.73 & 0.37 & 1.47 & 0.38 \\
\hline \multicolumn{18}{|l|}{$\begin{array}{l}\text { Menopausal } \\
\text { status }\end{array}$} \\
\hline Premenopausal & 120 & 1 & & & & & & & & 1 & & & & & & & \\
\hline Postmenopausal & 159 & 1.01 & 0.73 & 1.38 & 0.96 & & & & & 1.06 & 0.74 & 1.53 & 0.73 & & & & \\
\hline $\begin{array}{l}\text { Pathological } \\
\text { Tumor } \\
\text { classification }\end{array}$ & & & & & 0.009 & & & & 0.037 & & & & 0.017 & & & & 0.019 \\
\hline pT1 & 151 & 1 & & & & 1 & & & & 1 & & & & 1 & & & \\
\hline pT2 + unknown & 119 & 1.54 & 1.12 & 2.11 & 0.007 & 1.35 & 0.98 & 1.88 & 0.069 & 1.30 & 0.90 & 1.87 & 0.165 & 1.19 & 0.81 & 1.74 & 0.375 \\
\hline pT3+pT4 & 9 & 2.31 & 1.00 & 5.32 & 0.049 & 2.47 & 1.07 & 5.75 & 0.035 & 3.26 & 1.39 & 7.62 & 0.006 & 3.45 & 1.45 & 8.19 & 0.005 \\
\hline Grade & & & & & $\begin{array}{l}< \\
0.001\end{array}$ & & & & 0.001 & & & & 0.033 & & & & 0.082 \\
\hline poor & 131 & 1 & & & & 1 & & & & 1 & & & & 1 & & & \\
\hline unknown & 81 & 1.36 & 0.97 & 1.91 & 0.076 & 1.40 & 0.98 & 1.99 & 0.064 & 0.89 & 0.59 & 1.34 & 0.577 & 0.97 & 0.64 & 1.48 & 0.894 \\
\hline $\begin{array}{l}\text { moderate and } \\
\text { good }\end{array}$ & 67 & 0.52 & 0.33 & 0.82 & 0.004 & 0.57 & 0.36 & 0.89 & 0.014 & 0.51 & 0.31 & 0.85 & 0.009 & 0.57 & 0.34 & 0.94 & 0.029 \\
\hline ER & 279 & 1.11 & 0.98 & 1.25 & 0.10 & & & & & 0.99 & 0.86 & 1.14 & 0.92 & & & & \\
\hline \multicolumn{18}{|l|}{ PR } \\
\hline negative & 62 & 1 & & & & 1 & & & & 1 & & & & 1 & & & \\
\hline positive & 217 & 0.66 & 0.46 & 0.93 & 0.019 & 0.68 & 0.47 & 0.98 & 0.037 & 0.49 & 0.33 & 0.73 & $<.001$ & 0.56 & 0.37 & 0.85 & 0.007 \\
\hline \multicolumn{18}{|l|}{ HER2 status* } \\
\hline not amplified & 233 & 1 & & & & & & & & 1 & & & & 1 & & & \\
\hline \multirow[t]{2}{*}{ amplified } & 43 & 1.21 & 0.80 & 1.84 & 0.36 & & & & & 1.82 & 1.17 & 2.84 & 0.008 & 1.72 & 1.08 & 2.73 & 0.022 \\
\hline & & $\begin{array}{l}\text { Univa } \\
\text { PFS }\end{array}$ & iate mo & & & & & & & $\begin{array}{l}\text { Univa } \\
\text { post-r }\end{array}$ & $\begin{array}{l}\text { ate mo } \\
\text { lapse s }\end{array}$ & $\begin{array}{l}\text { del } \\
\text { urvival }\end{array}$ & & & & & \\
\hline $\begin{array}{l}\text { 1st line } \\
\text { Tamoxifen }\end{array}$ & 235 & & & & & & & & & & & & & & & & \\
\hline $\begin{array}{l}\text { at least one } \\
\text { ESR1-CCDC170 } \\
\text { (exon } 2 \text { to } 8 \text { ) } \\
\text { fusion }\end{array}$ & & 0.96 & 0.71 & 1.30 & 0.81 & & & & & 1.16 & 0.85 & 1.60 & 0.35 & & & & \\
\hline ESR1-AKAP12 & & 1.37 & 0.61 & 3.10 & 0.44 & & & & & 1.92 & 0.84 & 4.35 & 0.12 & & & & \\
\hline 1st line Al & 87 & & & & & & & & & & & & & & & & \\
\hline $\begin{array}{l}\text { at least one } \\
\text { ESR1-CCDC170 } \\
\text { (exon } 2 \text { to } 8 \text { ) } \\
\text { fusion }\end{array}$ & & 0.85 & 0.53 & 1.37 & 0.50 & & & & & & & & & & & & \\
\hline ESR1-AKAP12 & & 1.62 & 0.73 & 3.60 & 0.24 & & & & & & & & & & & & \\
\hline
\end{tabular}




\begin{tabular}{|c|c|c|c|c|c|c|c|c|c|c|c|c|c|c|c|c|c|}
\hline & & \multicolumn{4}{|c|}{ Univariate model DFS } & \multicolumn{4}{|c|}{ Multivariate model DFS } & \multicolumn{4}{|c|}{ Univariate model OS } & \multicolumn{4}{|c|}{ Multivariate model OS } \\
\hline & & & & & & $\begin{array}{l}\text { Sepa } \\
\text { mod }\end{array}$ & ately a & ded to $t$ & he base & & & & & & & & \\
\hline & & \multicolumn{4}{|c|}{ Univariate model DFS } & \multicolumn{4}{|c|}{ Multivariate model DFS } & \multicolumn{4}{|c|}{ Univariate model OS } & \multicolumn{4}{|c|}{ Multivariate model OS } \\
\hline \multicolumn{18}{|c|}{$\begin{array}{l}\text { at least one } \\
\text { ESR1-CCDC170 } \\
\text { (exon } 2 \text { to 8) } \\
\text { fusion }\end{array}$} \\
\hline negative & 213 & 1 & & & & 1 & & & & 1 & & & & 1 & & & \\
\hline positive & 66 & 1.44 & 1.01 & 2.05 & 0.044 & 1.33 & 0.92 & 1.92 & 0.13 & 1.67 & 1.13 & 2.47 & 0.010 & 1.54 & 1.02 & 2.33 & 0.042 \\
\hline \multicolumn{18}{|c|}{$\begin{array}{l}\text { ESR1-CCDC170 } \\
\text { (exon 2) fusion }\end{array}$} \\
\hline negative & 246 & 1 & & & & & & & & 1 & & & & 1 & & & \\
\hline positive & 33 & 1.40 & 0.89 & 2.21 & 0.14 & & & & & 1.75 & 1.07 & 2.87 & 0.026 & 1.38 & 0.82 & 2.33 & 0.22 \\
\hline \multicolumn{18}{|c|}{$\begin{array}{l}\text { ESR1-CCDC170 } \\
\text { (exon 8) fusion }\end{array}$} \\
\hline negative & 240 & 1 & & & & 1 & & & & 1 & & & & 1 & & & \\
\hline positive & 39 & 1.95 & 1.30 & 2.93 & 0.001 & 1.82 & 1.20 & 2.75 & 0.005 & 1.85 & 1.18 & 2.90 & 0.007 & 1.71 & 1.08 & 2.72 & 0.023 \\
\hline \multicolumn{18}{|c|}{ ESR1-AKAP12 } \\
\hline negative & 274 & 1 & & & & & & & & 1 & & & & & & & \\
\hline positive & 5 & 1.23 & 0.39 & 3.87 & 0.72 & & & & & 2.45 & 0.90 & 6.65 & 0.08 & & & & \\
\hline
\end{tabular}

DFS: Disease free survival; OS: Overall survival; ER: Estrogen Receptor; PR: Progesterone receptor; HER2: human epidermal growth factor receptor 2; PFS:

Progression free surival. *Due to the unknown data, numbers do not add up to 279 . Differences statistically significant are indicated in bold.

\section{Association of ESR1 fusion genes with clinical characteristics, PFS and post-relapse overall survival in advanced BC patients}

The fusion transcripts were related with traditional clinical parameters, with response to first-line endocrine therapy in the predictive cohort ( $\mathrm{n}=322$; tamoxifen $(\mathrm{n}=235)$, aromatase inhibitors $(\mathrm{n}=87)$ ) (Table 2). In the predictive cohort ESR1-CCDC170 fusion transcripts showed an association with age at start of first-line treatment, whereas ESR1-AKAP12 fusion transcripts were enriched in patients with progesterone-negative primary tumors at time of surgery and in Al-treated patients who received adjuvant tamoxifen. No relation with PFS after first-line tamoxifen $(\mathrm{n}=235)$ was found in our Cox proportional hazards regression survival analysis for the ESR1-CCDC170 fusion transcripts (HR $\pm 95 \% \mathrm{Cl}: 0.96(0.71-1.30), \mathrm{P}=0.81)$ nor for the ESR 1 -AKAP12 fusion transcripts (HR $\pm 95 \%$ $\mathrm{Cl}: 1.37(0.61-3.10), \mathrm{P}=0.44)$ (Table 5). In addition, the presence of these fusion transcripts did not affect the time from relapse to death (post-relapse survival, $\mathrm{HR} \pm 95 \% \mathrm{Cl}: 1.16(0.85-1.60), \mathrm{P}=0.35$ and $1.92(0.84-4.35), \mathrm{P}=0.12$, for ESR1 fusions with CCDC170 and AKAP12, respectively) (Table 5). Similarly, also no association with PFS for first-line aromatase inhibitors ( $\mathrm{n}=87)$ was found for ESR 1 -CCDC170 fusion transcripts (HR $\pm 95 \% \mathrm{Cl}$ : 0.85 ( $0.53-$ $1.37), \mathrm{P}=0.50)$ nor for the ESR1-AKAP12 fusion transcripts (HR $\pm 95 \% \mathrm{Cl}: 1.62(0.73-3.60), \mathrm{P}=0.24)$. With data available for only 27 patients post-relapse, we did not analyze post-relapse survival for aromatase inhibitors. Moreover, no-significant associations with PFS were seen when the ESR1-CCDC170 exon 2 and exon 8 fusion transcripts were analyzed separately (Table 5).

\section{Discussion}

The genetic landscape contributing to de novo or acquired resistance to endocrine therapy in breast cancer patients is not completely understood yet. In this study, we investigated the occurrence of recurrent fusion transcripts between ESR1 and three different loci adjacent to ESR1 (CCDC170, AKAP12 and ARMT1) and correlated their presence with clinical outcome. All of the fusion transcripts analyzed are recurrent and most frequently present in ER-positive disease and among them ESR1-CCDC170 fusion transcripts were the most predominant. As proposed by others [10,13], the presumption was that these fusion transcripts, which are considered to cause constitutive ER signaling, might signify resistance to endocrine therapy. However, in patients with advanced breast cancer, we did not find that the presence of any of these fusion transcripts is associated with outcome to endocrine therapy whether it concerned first line tamoxifen or an aromatase inhibitor. Importantly, smaller size effects from these the variants may be undetected due to the relatively small sample size of the study cohort, 87 patients treated with aromatase inhibitors and 235 subjects with tamoxifen. In contrast, in patients with primary BC and not receiving adjuvant systemic hormone treatments, we found that fusion between ESR1 and CCDC170 in general, and between exon 2 of ESR1 and exon 8 of $C C D C 170$ in particular, predicted in uni- and multivariable analyses shorter disease free survival as well as shorter overall survival. Thus, ESR1 and CCDC170 fusion transcript pinpoint cancers with an adverse outcome.

Understanding the molecular mechanisms that underlay the origin of fusion transcripts could help to comprehend the role of these fusions in carcinogenesis as well as improve the diagnosis of cancer patients $[10,13]$. Although the progress in DNA sequencing enhanced detection of recurrent and pathological breast cancer fusions, the complexity of underlying genomic rearrangement patterns makes their characterization at the DNA level often difficult. The fusion between $E S R 1$ and its neighboring gene $C C D C 170$ are potentially generated by tandem duplication $[9,13,21,22]$, which is also causing other genetic rearrangements in cancer $[9,23,24]$. Kim et al. found a region within the ESR1 genomic locus most vulnerable to DNA strand breakage, which often included 
intron 6 region of its neighboring gene CCDC170, resulting in oncogenic mRNA ESR1-CCDC170 fusion transcript of exons 2 of ESR1 connected to exon 2-11 of $C C D C 170$, i.e. the $\mathrm{C}$-terminal domain of CCDC170 [25]. Irrespective of mechanisms causing the gene fusions, they occur in a patient-specific manner, which makes their identification at the DNA level less suitable for routine diagnostics. Our method to analyze fusion transcripts is much less dependent on exact position of the underlying gene fusion at the DNA level and is therefore better suited to evaluate as a general biomarker in large patient cohorts. However, an important caveat for detecting gene fusions at the transcript level is the fact that it cannot distinguish between fusion transcripts arising from actual genetic rearrangements and those that arise from transcription reading from one gene into the next without a genetic cause. Finally, the generation of artefactual fusion sequences, which are randomly ligated during the sequencing procedure, might happen, as previously reported by Veeraraghavan et al. [13]. Overall, we performed RT-qPCR analysis and investigated RNA not DNA, therefore we cannot tell whether fusion transcripts are the results of (DNA) rearrangements.

Another interesting question regards the biological significance of clinically relevant fusion transcripts. Gene fusions and their products (RNAs and proteins) are assumed to be exclusive to cancer. However, RNA-sequencing analyses from normal appearing margins of cancerous specimens showed fusion transcripts also in normal tissues [26]. In fact, oncogenic rearrangements, such as the EML4-ALK [27], NPM-ALK [28], JAZF1-JJAZ1 [29] and BCR-ABL 1 [30] fusions are also expressed at a low level in histologically non-neoplastic tissues [9]. In our study, expression of ESR1 fused to exons 2 and exon 8 of $C C D C 170$ was found in mammary epithelial tissues derived from women without diagnosis of breast cancer, and in cases with (benign) fibroadenomas, respectively. Also in early stages of breast cancer, like DCIS, we detected fusion transcripts. Moreover, ESR1-CCDC170 fusion transcripts were also detected in normal breast tissues of patients with diagnosed breast cancer. This argues that a percentage may be transcript read-through instead of fusion transcripts arising from gene fusions.

According to our results, the expression of ESR1-CCDC170 exon 2 and exon 8 fusion transcripts were linked to a less favorable disease in BC patients who not received adjuvant systemic treatment. Overall, our results are in agreement with those reported by Veeraraghavan et al. which showed that ESR1-CCDC170 fusions, when introduced into ER-positive breast cancer cells, leads to a markedly increase of cell motility and colony-forming ability, increase in S-G2/M phase cells and a decrease in G0/G1 phase cells. Although several functional studies $[9,31]$ demonstrated a role of ESR1-CCDC170 fusions in endocrine therapy resistance, no relationship between fusion transcripts and treatment outcome was observed in our predictive cohort. Overall, since ESR1-CCDC170 fusions in our study demonstrated no predictive value for endocrine therapy resistance, their prognostic value might be explained by the recurrent incidence of read-through events during cell cycle progression. This latter has been exemplified with the abundance of CTSD-IFITM10 readthrough fusions during breast cancer cell proliferation [32].

\section{Conclusions}

The most important conclusion from our work is that among the fusion transcripts evaluated measuring ESR 1-CCDC170 exon 8 fusion transcripts in primary breast cancers has diagnostic potential as it identifies a more aggressive subset of ER-positive breast cancer patients. Furthermore, with our study we demonstrated that ESR1-CCDC170 fusion transcript does not predict endocrine therapy resistance in our setting.

\section{Abbreviations}

Al: aromatase inhibitor; ARMT1: Acidic Residue Methyltransferase 1; AKAP12: A-Kinase Anchoring Protein 12; BC: breast cancer; CCDC170: Coiled-Coil Domain Containing 170; DCIS: ductal carcinomas in situ; DFS: disease- free survival; ER: estrogen receptor; ERBB2: Erb-B2 Receptor Tyrosine Kinase 2; ESR1: estrogen receptor alpha; ET: endocrine therapy; HPRT1: Hypoxanthine Phosphoribosyltransferase 1; HR: Hazard ratio; IHC: immunohistochemical staining; LBD: ligand-binding domain; LNN: lymph node negative; LNP: Lymph node positive; OS: Overall survival; PFS: progression free survival; PR: Progesterone receptor; RT-qPCR: reverse transcriptase quantitative PCR; TAM: Tamoxifen.

\section{Declarations}

Ethics approval and consent to participate: The protocol of the study was approved by the medical ethics committee of the Erasmus Medical Centre Rotterdam, The Netherlands (MEC 02.953) and was performed in accordance with the Code of Conduct of the Federation of Medical Scientific Societies in The Netherlands (https://www.federa.org/codes-conduct). The use of coded left-over material for scientific purposes does not require informed consent according to Dutch law and the new European general data protection regulation (GDPR).

Consent for publication: Not applicable

Availability of data and materials: All data generated or analysed during this study are included in this published article and its supplementary information files.

Disclosures: None declared.

Grants and acknowledgements: AMS and JWM were supported by the Cancer Genomics Netherlands (CGC.nl)/Netherlands Organization for Scientific Research (NWO). SRV was supported by an ERC Advanced grant (No 322737). The authors are especially grateful to all patients, to Steven van Laere and Luc Dirix - Department Oncology, Antwerp University, Belgium and to Sabine C. Linn - Department of Medical Oncology, Netherlands Cancer Institute, Amsterdam, the Netherlands for their contribution of tissues from patients treated with $1^{\text {st }}$ line aromatase inhibitor.

Authors' contributions: SRV and AMS designed the study; SRV, KR-R, CB, AMT, RF, AMT-J and AMS performed the laboratory experiments (RT-qPCR, western blotting analyses and immunohistochemical stainings). AMS and MPHMJ analyzed the data and compiled statistics; JWM and MPHMJ supplied the patient 
materials (tissues and clinical information); PV, SS and JWM supervised the study and provided the financial budget; SRV, AMS and MPHMJ wrote the manuscript, which was reviewed, edited and approved by all authors.

\section{References}

1. Pritchard KI: Endocrine therapy: is the first generation of targeted drugs the last? J Intern Med 2013, 274:144-152.

2. Riggins RB, Schrecengost RS, Guerrero MS, Bouton AH: Pathways to tamoxifen resistance. Cancer Lett 2007, 256:1-24.

3. Osborne CK, Schiff R: Mechanisms of endocrine resistance in breast cancer. Annu Rev Med 2011, 62:233-247.

4. Schiavon G, Hrebien S, Garcia-Murillas I, Cutts RJ, Pearson A, Tarazona N, Fenwick K, Kozarewa I, Lopez-Knowles E, Ribas R, et al: Analysis of ESR1 mutation in circulating tumor DNA demonstrates evolution during therapy for metastatic breast cancer. Sci Trans/ Med 2015, 7:313ra182.

5. Pejerrey SM, Dustin D, Kim JA, Gu G, Rechoum Y, Fuqua SAW: The Impact of ESR1 Mutations on the Treatment of Metastatic Breast Cancer. Horm Cancer 2018, 9:215-228.

6. Beije N, Sieuwerts AM, Kraan J, Van NM, Onstenk W, Vitale SR, van der Vlugt-Daane M, Dirix LY, Brouwer A, Hamberg P, et al: Estrogen receptor mutations and splice variants determined in liquid biopsies from metastatic breast cancer patients. Mol Oncol 2018, 12:48-57.

7. Vitale SR, Sieuwerts AM, Beije N, Kraan J, Angus L, Mostert B, Reijm EA, Van NM, van Marion R, Dirix LY, et al: An Optimized Workflow to Evaluate Estrogen Receptor Gene Mutations in Small Amounts of Cell-Free DNA. J Mol Diagn 2019, 21:123-137.

8. Robinson DR, Kalyana-Sundaram S, Wu YM, Shankar S, Cao X, Ateeq B, Asangani IA, lyer M, Maher CA, Grasso CS, et al: Functionally recurrent rearrangements of the MAST kinase and Notch gene families in breast cancer. Nat Med 2011, 17:1646-1651.

9. Veeraraghavan J, Tan Y, Cao XX, Kim JA, Wang X, Chamness GC, Maiti SN, Cooper LJ, Edwards DP, Contreras A, et al: Recurrent ESR1-CCDC170 rearrangements in an aggressive subset of oestrogen receptor-positive breast cancers. Nat Commun 2014, 5:4577.

10. Giltnane JM, Hutchinson KE, Stricker TP, Formisano L, Young CD, Estrada MV, Nixon MJ, Du L, Sanchez V, Ericsson PG, et al: Genomic profiling of ER(+) breast cancers after short-term estrogen suppression reveals alterations associated with endocrine resistance. Sci Trans/ Med $2017,9$.

11. Li S, Shen D, Shao J, Crowder R, Liu W, Prat A, He X, Liu S, Hoog J, Lu C, et al: Endocrine-therapy-resistant ESR1 variants revealed by genomic characterization of breast-cancer-derived xenografts. Cell Rep 2013, 4:1116-1130.

12. Yoshihara K, Wang Q, Torres-Garcia W, Zheng S, Vegesna R, Kim H, Verhaak RG: The landscape and therapeutic relevance of cancer-associated transcript fusions. Oncogene 2015, 34:4845-4854.

13. Veeraraghavan J, Ma J, Hu Y, Wang XS: Recurrent and pathological gene fusions in breast cancer: current advances in genomic discovery and clinical implications. Breast Cancer Res Treat 2016, 158:219-232.

14. Sieuwerts AM, Meijer-van Gelder ME, Timmermans M, Trapman AM, Garcia RR, Arnold M, Goedheer AJ, Portengen H, Klijn JG, Foekens JA: How ADAM-9 and ADAM-11 differentially from estrogen receptor predict response to tamoxifen treatment in patients with recurrent breast cancer: a retrospective study. Clin Cancer Res 2005, 11:7311-7321.

15. Sieuwerts AM, Usher PA, Meijer-van Gelder ME, Timmermans M, Martens JW, Brunner N, Klijn JG, Offenberg H, Foekens JA: Concentrations of TIMP1 mRNA splice variants and TIMP-1 protein are differentially associated with prognosis in primary breast cancer. Clin Chem 2007, 53:1280-1288.

16. Ramirez-Ardila DE, Helmijr JC, Look MP, Lurkin I, Ruigrok-Ritstier K, van Laere S, Dirix L, Sweep FC, Span PN, Linn SC, et al: Hotspot mutations in PIK3CA associate with first-line treatment outcome for aromatase inhibitors but not for tamoxifen. Breast Cancer Res Treat 2013, 139:39-49.

17. Hayward JL, Rubens RD, Carbone PP, Heuson JC, Kumaoka S, Segaloff A: Assessment of response to therapy in advanced breast cancer. A project of the programme on clinical oncology of the International Union against Cancer, Geneva, Switzerland. Eur J Cancer 1978, 14:1291-1292.

18. Onstenk W, Sieuwerts AM, Kraan J, Van M, Nieuweboer AJ, Mathijssen RH, Hamberg P, Meulenbeld HJ, De Laere B, Dirix LY, et al: Efficacy of Cabazitaxel in Castration-resistant Prostate Cancer Is Independent of the Presence of AR-V7 in Circulating Tumor Cells. Eur Urol 2015, 68:939-945.

19. Sieuwerts AM, Kraan J, Bolt-de Vries J, van der Spoel P, Mostert B, Martens JW, Gratama JW, Sleijfer S, Foekens JA: Molecular characterization of circulating tumor cells in large quantities of contaminating leukocytes by a multiplex real-time PCR. Breast Cancer Res Treat 2009, 118:455-468.

20. Sieuwerts AM, Mostert B, Bolt-de Vries J, Peeters D, de Jongh FE, Stouthard JM, Dirix LY, van Dam PA, Van Galen A, de Weerd V, et al: mRNA and microRNA expression profiles in circulating tumor cells and primary tumors of metastatic breast cancer patients. Clin Cancer Res 2011, 17:3600-3618.

21. Lei JT, Gou X, Ellis MJ: ESR1 fusions drive endocrine therapy resistance and metastasis in breast cancer. Mol Cell Oncol $2018,5: e 1526005$.

22. Paratala BS, Dolfi SC, Khiabanian H, Rodriguez-Rodriguez L, Ganesan S, Hirshfield KM: Emerging Role of Genomic Rearrangements in Breast Cancer: Applying Knowledge from Other Cancers. Biomark Cancer 2016, 8:1-14.

23. Jones DT, Kocialkowski S, Liu L, Pearson DM, Backlund LM, Ichimura K, Collins VP: Tandem duplication producing a novel oncogenic BRAF fusion gene defines the majority of pilocytic astrocytomas. Cancer Res 2008, 68:8673-8677.

24. Lipson D, Capelletti M, Yelensky R, Otto G, Parker A, Jarosz M, Curran JA, Balasubramanian S, Bloom T, Brennan KW, et al: Identification of new ALK and RET gene fusions from colorectal and lung cancer biopsies. Nat Med 2012, 18:382-384.

25. Kim RN, Moon HG, Han W, Noh DY: Perspective Insight into Future Potential Fusion Gene Transcript Biomarker Candidates in Breast Cancer. Int J Mol Sci 2018, 19.

26. Babiceanu M, Qin F, Xie Z, Jia Y, Lopez K, Janus N, Facemire L, Kumar S, Pang Y, Qi Y, et al: Recurrent chimeric fusion RNAs in non-cancer tissues and cells. Nucleic Acids Res 2016, 44:2859-2872.

27. Martelli MP, Sozzi G, Hernandez L, Pettirossi V, Navarro A, Conte D, Gasparini P, Perrone F, Modena P, Pastorino U, et al: EML4-ALK rearrangement in nonsmall cell lung cancer and non-tumor lung tissues. Am J Pathol 2009, 174:661-670. 
28. Maes B, Vanhentenrijk V, Wlodarska I, Cools J, Peeters B, Marynen P, de Wolf-Peeters C: The NPM-ALK and the ATIC-ALK fusion genes can be detected in non-neoplastic cells. Am J Pathol 2001, 158:2185-2193.

29. Li H, Wang J, Mor G, Sklar J: A neoplastic gene fusion mimics trans-splicing of RNAs in normal human cells. Science 2008, 321:1357-1361.

30. Biernaux C, Loos M, Sels A, Huez G, Stryckmans P: Detection of major bcr-abl gene expression at a very low level in blood cells of some healthy individuals. Blood 1995, 86:3118-3122.

31. Li Li JV, Yiheng Hu, Xian Wang, Ying Tan, Rachel Schiff and Xiaosong Wang: Abstract 376: Therapeutic role of ESR1-CCDC170 gene fusion in breast cancer endocrine resistance. American Association for Cancer Research 2019, 79:Supplement, pp. 376.

32. Varley KE, Gertz J, Roberts BS, Davis NS, Bowling KM, Kirby MK, Nesmith AS, Oliver PG, Grizzle WE, Forero A, et al: Recurrent read-through fusion transcripts in breast cancer. Breast Cancer Res Treat 2014, 146:287-297.

\section{Figures}

A
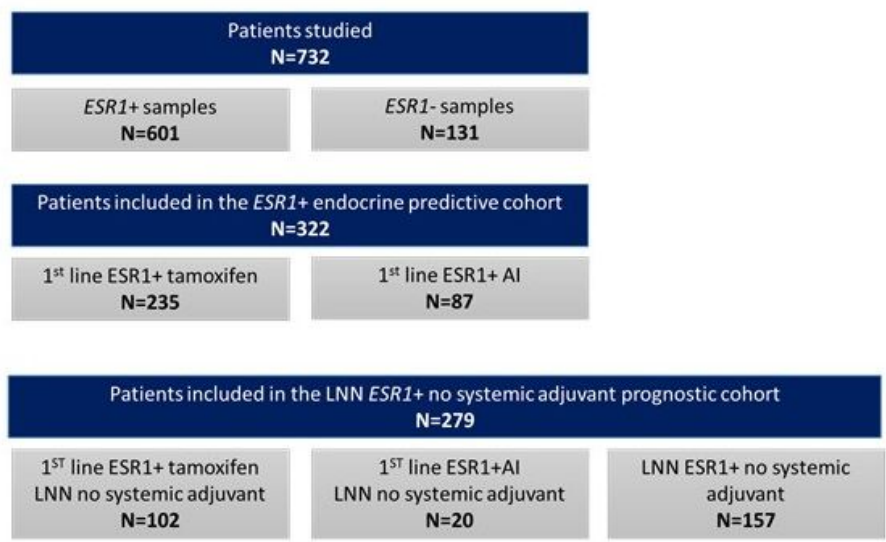

B

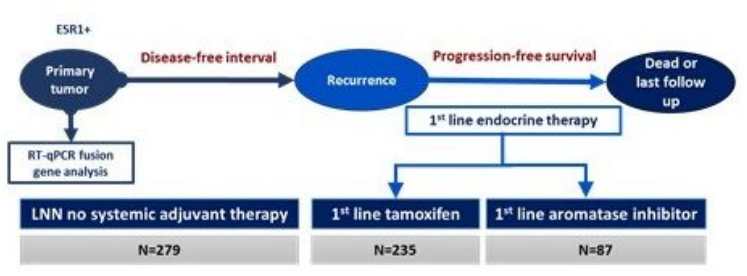

Figure 1

Figure 1

Overview of the study and selection of available patients. A) Flow diagram of the study; B) Workflow of processing samples: fusion gene mRNA levels were measured in 322 ER-positive primary tumors (predictive cohort) by quantitative reverse transcriptase PCR (RT-qPCR). All patients in this cohort were hormonenaïve and all experienced a disease recurrence and subsequently received 1st line endocrine therapy. The association of the presence of ESR1 fusion genes in the primary tumor progression-free survival (PFS) after start with 1 st line tamoxifen $(n=235)$ or aromatase inhibitors $(n=87)$, were evaluated. Similarly, disease free interval (DFS) and overall survival (OS) were investigated in 279 lymph node negative ER-positive breast cancer patients (prognostic cohort) who had not received any (neo)adjuvant systemic therapy. ESR1: Estrogen Receptor 1 gene; Al: Aromatase Inhibitor; LNN: Lymph node negative; ER: Estrogen Receptor; RTqPCR: Quantitative reverse transcriptase PCR. 


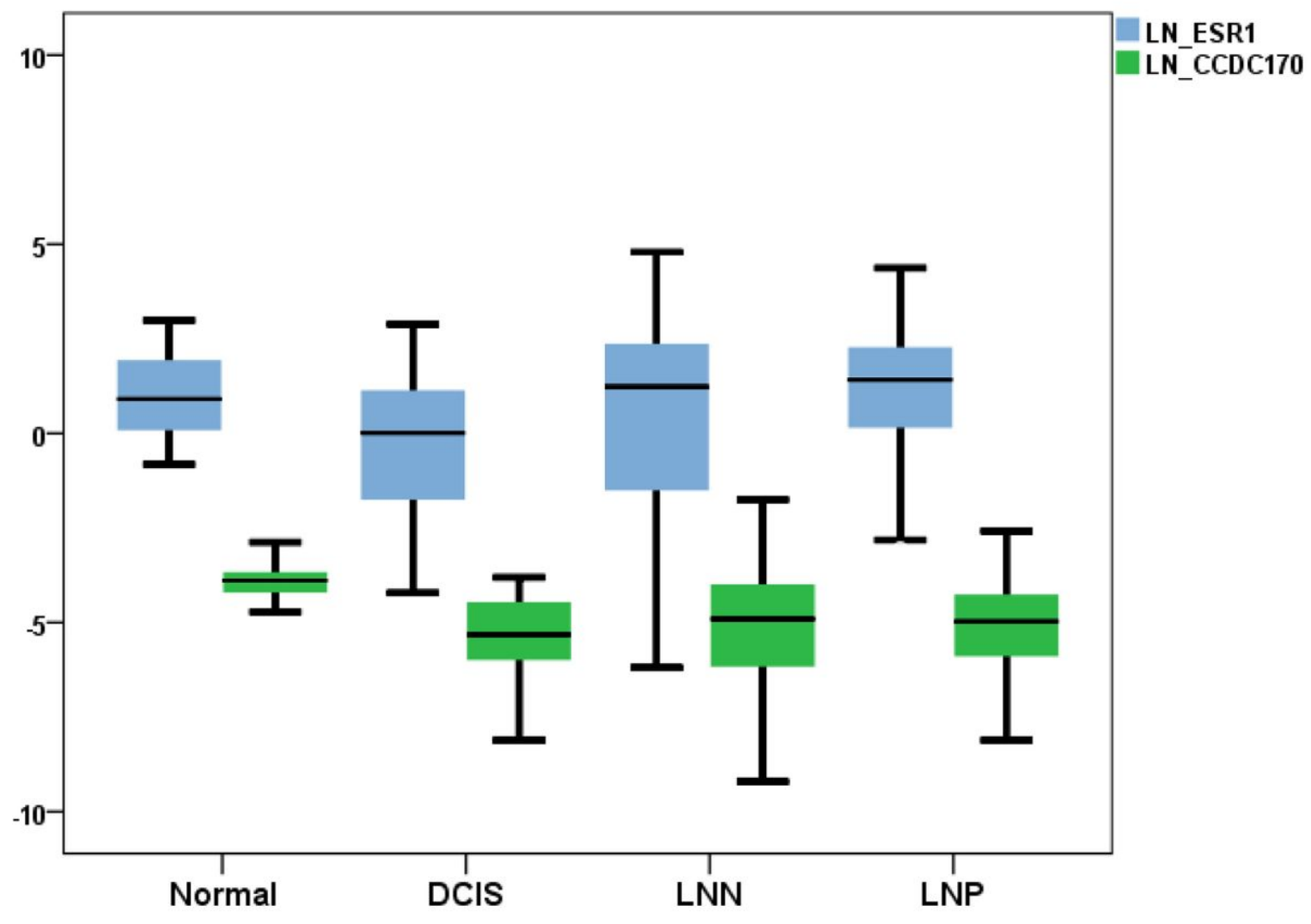

Figure 2

Figure 2

Expression of ESR1 and CCDC170 genes in breast tissues. CCDC170 (blue box) and ESR1 (green box) mRNA levels are showed in the y-axis and were measured by RT-qPCR in normal (adjacent to tumor), benign (DCIS) and carcinoma (LNN and LNP) breast tissues. The box plots show interquartile ranges (IQR) together with the median (black horizontal line) of the ESR1 and CCDC170 mRNA levels for the different conditions. DCIS: ductal carcinomas in situ; LNP: Lymph node positive; LNN: Lymph node negative. 

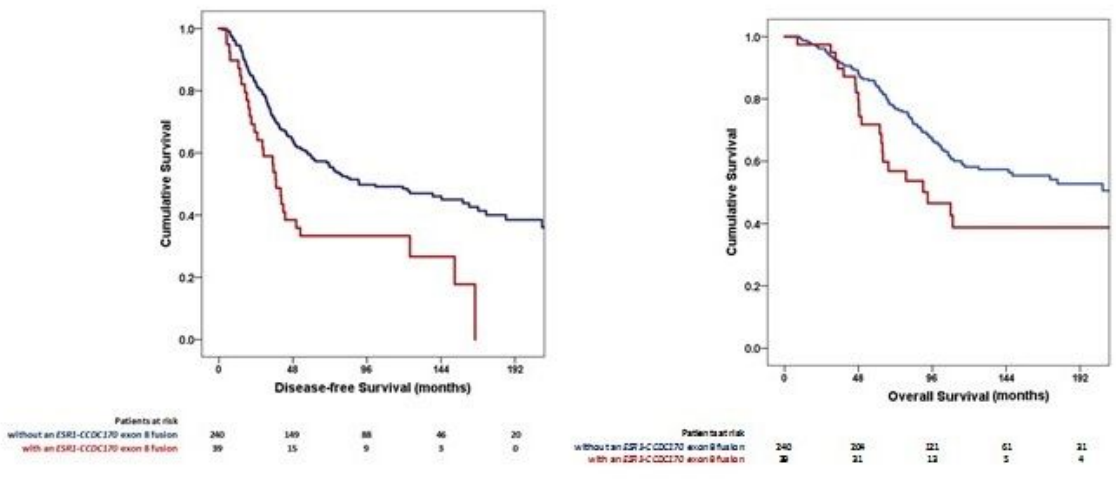

Figure 3

Figure 3

Disease free survival (DFS) and overall survival (OS) in the prognostic cohort. The DFS and OS Kaplan Meier curves in positive LNN patients. A) DFS of patients with or without ESR1-CCDC170 exon 8 fusion gene; (B) OS of patients with or without ESR1-CCDC170 exon 8 fusion gene. The reported P-value is from a log-rank test and the test statistics from Cox regression analyses.

\section{Supplementary Files}

This is a list of supplementary files associated with this preprint. Click to download.

- AdditionalFile3BMCCancer.jpg

- AdditionalFile4BMCCancer.jpg

- AdditionalFile7BMCCancer.jpg

- AdditionalFileFusionpaperBMCCancer.xIsx 